\title{
Efeitos da estabulação sobre o trato respiratório de equinos em dois tipos diferentes de camas e a pasto
} https://orcid.org/0000-0002-1223-9903 J.C. Lacerda Neto

\author{
[Stabling effects on equine respiratory tract using \\ two different types of stable beds and pasture] \\ K. Calciolari, K. Gravena' N.S. Bernardi, \\ D.J. Queiroz, J.C. Lacerda Neto
}

Universidade Estadual Paulista - Jaboticabal, SP

\begin{abstract}
RESUMO
As afecções do sistema respiratório são a segunda causa de queda de desempenho e afastamento dos equinos do esporte ou trabalho, as quais estão atrás somente das desordens musculoesqueléticas. A estabulação e a alimentação à base de fenos predispõem os equinos à inalação de grande número de agentes irritantes às vias aéreas. No intuito de avaliar a influência dos tipos de cama utilizados em baias, estudaram-se três grupos de cinco equinos cada, durante 45 dias. Dois grupos foram mantidos em cocheiras com forrações diferentes à base de madeira (maravalha de pínus autoclavada-MA e serragem$\mathrm{SE}$ ) e o terceiro grupo permaneceu no pasto. Foram realizadas avaliações quinzenais, que incluíram exame físico, hemograma, hemogasometria e lavado broncoalveolar. Ao exame físico, notou-se a presença de tosse e espirros em animais do grupo SE. No lavado broncoalveolar, a contagem de células nucleadas totais apresentou maiores valores nos animais a pasto, seguido do grupo SE e, por último, o MA. Concluiu-se que as duas camas testadas neste estudo não apresentaram diferença com relação à capacidade irritativa das vias aéreas superiores no período analisado.
\end{abstract}

Palavras-chave: cavalos, lavado broncoalveolar, maravalha, serragem, alergia

\begin{abstract}
Respiratory system affections in horses are the second cause of decrease in performance and removal from the sport or farm work, which are behind only the musculoskeletal disorders. Stabling and hay feeding predisposes horses' airways to inhalation of large numbers of irritating agents. To evaluate the influence of bed types used in bays, 3 groups of 5 horses each were studied for 45 days. Two groups were kept in stables with different wood beds - based rafters (autoclaved pine - MA and sawdust - SE) and the third group remained in the pasture. Biweekly evaluations with physical examination, hemogram, hemogasometry and bronchoalveolar lavage were performed. On physical examination, the presence of cough and sneezing was observed in animals of the SE group. In the bronchoalveolar lavage, the total nucleated cell count presented higher values in the animals in the pasture, followed by the SE group and finally the MA. It was concluded that the different beds used presented no difference with respect to the irritative capacity of the upper airways.
\end{abstract}

Keywords: horses, bronchoalveolar lavage, shavings, sawdust, allergy

\section{INTRODUÇÃO}

O sistema respiratório tem a função de captar e fornecer oxigênio $\left(\mathrm{O}_{2}\right)$ aos tecidos assim como remover o dióxido de carbono $\left(\mathrm{CO}_{2}\right)$, um dos

Recebido em 29 de janeiro de 2018

Aceito em 26 de março de 2019

E-mail: karinaveterinaria@yahoo.com produtos do metabolismo celular (Robinson e Furlow, 2007; Thomassian, 2012). Com isso, o epitélio do sistema respiratório é exposto a partículas dispersas no ar (orgânicas e inorgânicas) e a fatores ambientais (umidade relativa e temperatura do ar), os quais podem desencadear patologias de caráter alérgico 
(Horohov, 2004; Thacker, 2006). Assim, as vias aéreas dispõem de funções protetoras, celular, físicas e químicas, as quais atuam contra as adversidades a que o ar aspirado pode expor o epitélio desse sistema (Thomassian, 2012). O mecanismo físico se dá pela remoção mecânica das partículas na cavidade nasal, na orofaringe e na traqueia, pela tosse, pelo espirro e pelo mecanismo de clearance mucociliar (Pilette et al., 2001). O mecanismo de defesa celular é caracterizado pela liberação de mediadores próinflamatórios, anticorpos e agentes químicos, que trabalham em conjunto contra a exposição do sistema respiratório a agentes irritantes (feno, mofos, esporos de fungos, insetos, bactérias e vírus) (Hume, 2008; Guth et al., 2009). A irritação das vias aéreas pode ainda desencadear mecanismos químicos como a liberação de histamina local, resultando em vasodilatação e aumento da permeabilidade vascular. $\mathrm{O}$ influxo de fluidos traz consigo fagócitos, mastócitos, células ativadas (mecanismo celular de proteção) e fibrinogênio.

O processo inflamatório nas vias aéreas leva ao comprometimento das trocas gasosas e, consequentemente, ao aumento da concentração de dióxido de carbono, causando a acidose respiratória (diagnosticada com base na análise hemogasométrica do sangue arterial) (Coüetil et al., 2007). O conjunto dessas reações resulta em secreção mucoide pelas narinas, edema, broncoconstricção, alteração da frequência e profundidade respiratória, síndrome de espirros típica até tosse crônica (Lunn et al., 2007; Wilkins, 2009). Algumas alterações, como febre e desvios hematológicos indicando infecção, são excludentes de afecções alérgicas (Coüetil et al., 2007).

Quanto aos métodos de avaliação do sistema respiratório, além da anamnese e de exame físico, há métodos laboratoriais que auxiliam no diagnóstico. A análise dos gases sanguíneos quantifica o grau de absorção de oxigênio e a remoção de dióxido de carbono (Clutton, 2007), podendo determinar, caso esteja presente, o grau de insuficiência pulmonar (Wiedmeyer, 2012). O lavado broncoalveolar (LBA) consiste na instilação de fluidos nas vias aéreas e posterior coleta, na qual obtém-se amostra do líquido assim como grande porcentagem das células que revestem o epitélio de porções distais do trato respiratório (Ito et al., 2003). Por meio da avaliação citológica do lavado broncoalveolar, tem-se um método sensível de se monitorar objetivamente as vias aéreas inferiores e auxiliar no diagnóstico de doenças generalizadas ou não infecciosas, como a ORVA (Hoffman et al., 2003; Hewson e Viel, 2002; Ito et al., 2003; Taylor et al., 2010).

O ambiente das cocheiras está relacionado ao aumento da porcentagem de neutrófilos no LBA, tanto em equinos normais quanto naqueles susceptíveis ou com histórico de doença das vias aéreas. O que diferencia os dois grupos é a intensidade da resposta inflamatória (Tremblay et al., 1993; Leclere et al., 2011). Além dos sinais clínicos descritos e dos achados laboratoriais (hemogasometria e lavado broncoalveolar), faz-se necessária ainda a identificação de fatores ambientais como possíveis fatores alergênicos: tipo de ração, cama, feno e condições das instalações (Wilkins, 2009; Ainsworth e Cheetham, 2010). O tipo de alojamento ou de pastejo, o espaço aéreo, a ventilação, a sanidade, a densidade de ocupação e a poeira são fatores importantes a serem analisados (Derksen e Woods, 1994). O manejo, as condições dos estábulos, a alimentação e o tipo de cama utilizado para forração podem desenvolver um ambiente propício ao aparecimento de doenças respiratórias de caráter alérgico. Ambientes fechados, feno mal armazenado e camas altamente pulverizáveis culminam no acúmulo de partículas de origem orgânica e inorgânica, compostas de fragmentos como grãos, plantas, fezes, agentes contagiosos e esporos de fungos, sendo este último o principal alérgeno incriminado no desencadeamento de enfermidades respiratórias em equinos (Coüetil et al., 2007; Bernedt et al., 2008).

\section{MATERIAL E MÉTODOS}

Foram utilizados 15 equinos hígidos, adultos, 10 machos e cinco fêmeas, sem raça definida, com idade média de $14,6 \pm 4,03$ anos e peso médio de $402,1 \pm 30,4$ quilos. O estudo foi aprovado pela Comissão de Ética no Uso de Animais (Ceua) da Faculdade de Ciências Agrárias e Veterinárias, Unesp - Campus de Jaboticabal/SP, sob o número de protocolo 21034/15. Previamente ao início do período experimental, os equinos foram submetidos a programa de vermifugação (Eqvalan $^{\circledR}$, Ivermectina, Merial Saúde Animal Ltda., Brasil) e a controle de ectoparasitas 
(Butox ${ }^{\circledR}$ P CE 25, Deltrametrina, Intervet Brasil - Akzo Nobel Ltda., Brasil).

Os equinos foram separados em três grupos: o primeiro permaneceu em piquete com forrageiras (Tifton) escassas (PASTO); o segundo foi alocado em baias individuais com cama de maravalha autoclavada de pínus (Fig. 1B) (Pinus elliottii) (MA); e o terceiro grupo foi alocado em baias com cama de serragem de madeiras diversas não tratadas (Fig. 1A) (SE). As baias possuíam piso cimentado sobre o qual foram colocados aproximadamente $15 \mathrm{~cm}$ de substrato. Os animais estabulados foram alojados em um pavilhão com 14 baias, e entre os grupos foram deixadas duas baias vazias para separá-los.

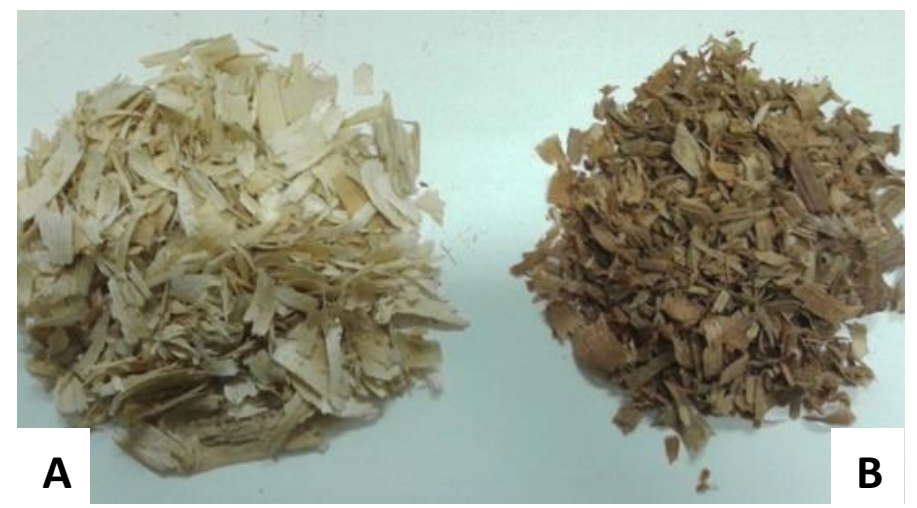

Figura 1. Foto comparativa dos dois tipos de cama utilizados nas baias. A) Maravalha autoclavada (MA). B) Serragem (SE).

Todos os animais receberam concentrado comercial peletizado em quantidade equivalente a $1 \%$ do peso corpóreo, volumoso de feno de Tifton pré-secado e água ad libitum. A higienização das baias foi diária, sendo os animais retirados do ambiente durante $o$ procedimento. Os equinos passaram por avaliações física, hematológica, hemogasométrica e de lavado broncoalveolar (LBA) a cada 15 dias. A primeira aferição, momento zero, foi realizada com todos os equinos alocados no piquete (M0), e, então, os animais foram divididos nos grupos PASTO, MA e SE. Posteriormente, as coletas foram realizadas em intervalos de 15 dias (M15, M30 e M45). A avaliação física baseou-se na auscultação torácica com a mensuração das frequências cardíaca (batimentos por minuto, bmp) e respiratória (movimentos por minuto, mpm), além de temperatura corpórea. Os sinais respiratórios, como presença de tosse e espirros, foram observados durante a higienização das baias ou oferta de feno e classificados em escores: escore 0 - inexistentes; escore 1 poucas vezes ao dia; escore 2 - muitas vezes ao dia.

Para avaliação da temperatura e umidade relativa do ar, foram utilizados dados meteorológicos convencionais, coletados durante todo o período experimental pela estação agroclimática da mesma instituição (lat. $21^{\circ} 15^{\prime} 22^{\prime \prime} \mathrm{S}$, long. $48^{\circ}$ 18 '58"W e altitude de 595 metros).

Após as coletas de sangue venoso da veia jugular mediante o uso de agulha estéril $(25 \times 8 \mathrm{~mm}, \mathrm{BD}$ Vacutainer $^{\circledR}$, Brasil) e de tubos estéreis com EDTA (5mL, BD Vacutainer ${ }^{\circledR}$ EDTA K2, Brasil), realizou-se hemograma em analisador hematológico veterinário (pocH-100iV Diff ${ }^{\circledR}$, SYSMEX, Japão), com posterior contagem diferencial de leucócitos. No plasma, foi mensurada a concentração de fibrinogênio, assim como Blaisdell e Dobds (1977) descrevem. Amostras de sangue arterial também foram coletadas, previamente ao LBA, da artéria transversa facial com agulha $25 \times 08$ e seringa própria para hemogasometria $\left(\mathrm{BD}^{\circledR}\right.$, A-line ${ }^{\mathrm{TM}}$ LUER LOK, Brasil). Essas amostras foram processadas em até cinco minutos, em analisador de múltiplos parâmetros do sistema Cobas $b 123$ (Roche ${ }^{\circledR}$ Diagnóstica Ltda., Brasil).

Para realização do $\mathrm{LBA}$, os equinos foram sedados com xilazina $10 \% \quad(0,05 \mathrm{mg} / \mathrm{kg})$ (Sedomin $^{\circledR}$, cloridrato de xilazina, König SA, Brasil) e, após cinco minutos, realizou-se a sondagem com a sonda flexível própria para 
coleta de LBA (Mila ${ }^{\circledR}$, Large Animal Bronchoalveolar Lavage Catheter, MILA internacional, Estados Unidos da América) de acordo com técnica descrita por Hewson e Viel (2002). Foram instilados $20 \mathrm{~mL}$ de solução de cloridrato de lidocaína 0,4\% (Xylestesin ${ }^{\circledR} 2 \%$, cloridrato de lidocaína, Cristália, Brasil), em salina estéril (Solução Fisiológica de Cloreto de Sódio $0,9 \%$, Equiplex ${ }^{\circledR}$, Brasil), no intuito de minimizar reações de hipersensibilidade e reflexo de tosse. Com o posicionamento correto da sonda, inflou-se o manguito, sendo infundidos $180 \mathrm{~mL}$ de salina estéril $(\mathrm{NaCl} 0,9 \%)$ que, em seguida, foi aspirada gentilmente. O volume recuperado foi mantido refrigerado para as análises, que ocorriam em até três horas, como indicam Viel e Hewson (2001). Uma alíquota de LBA total homogeneizado foi depositada em câmaras de Neubauer para contagem de células nucleadas totais (CNT) e eritrócitos (ER). Para análise citológica diferencial (porcentagem de neutrófilos, linfócitos, eosinófilos, macrófagos e mastócitos), o LBA total foi centrifugado a $1.300 \mathrm{rpm}$, por seis minutos, a $4^{\circ} \mathrm{C}$, obtendo-se pellet celular, sendo colocado em citocentrífuga para produção de lâminas de microscopia. As lâminas foram coradas com coloração panótico (Panótico Rápido LB ${ }^{\circledR}$, Laborclin, Brasil) rápido, fixadas e analisadas em microscópio óptico.

Para a análise das variáveis do hemograma e da hemogasometria e para a análise climatológica, o delineamento utilizado foi de parcelas subdivididas, com medidas repetidas no tempo, testando-se o fator grupo (três níveis) nas parcelas e o fator momento (quatro níveis) nas subparcelas, com cinco repetições por grupo. $\mathrm{O}$ quadrado médio de animal dentro do grupo foi usado como resíduo para testar o efeito de grupo. Havendo diferença significativa entre médias, estas foram comparadas entre si pelo teste de Tukey, ao nível de significância de 5\%. Para tanto, foi utilizado o procedimento "General Linear Models" (GLM) na primeira análise e o procedimento Npar1way na segunda, ambos do programa computacional SAS (SAS 9.1, SAS Institute, Cary, Estados Unidos da América).

\section{RESULTADOS E DISCUSSÃO}

Dentre os parâmetros avaliados no exame físico, como a frequência cardíaca, a respiratória e a temperatura retal, não houve alterações $(\mathrm{P}>0,05)$. $\mathrm{Na}$ análise dos sinais clínicos da irritação das vias aéreas, o grupo SE obteve escore 2 a partir do momento D15, permanecendo até o final da avaliação experimental. Um dos animais do grupo MA apresentou escore 1 apenas no momento D30, manifestando melhora no momento D45, no qual obteve escore 0, e um outro animal do grupo PASTO também apresentou escore 1 em D30, porém permaneceu com os sintomas até D45 (Fig. 2).

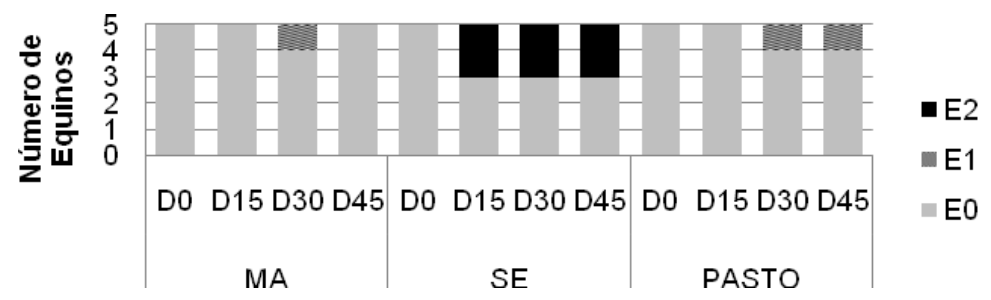

Figura 2. Sinais clínicos referentes à irritação das vias aéreas em 15 equinos mensurados em escores de 0 a 2 (E0: ausência de sinais clínicos, E1: tosse e espirros esporádicos e E2: tosse e espirros persistentes). Animais divididos em três grupos para comparação, sendo MA: cama de maravalha autoclavada, SE: cama de serragem comum e PASTO: equinos mantidos em piquete.

Os autores Viel (2009), McGorum e Dixon (2007) frisam a importância do exame físico detalhado associado ao histórico dos animais para localizar a origem e a localização das afecções. O exame clínico prévio, além do histórico conhecido dos equinos, favoreceu a exclusão de doenças respiratórias, confirmando que os sintomas e achados laboratoriais foram em resposta ao protocolo experimental ao qual os animais estavam sendo submetidos. Os equinos que apresentaram tosse seca de início agudo, alta, áspera e de caráter não produtivo se encaixaram na descrição de Wilkins (2009), o qual relata o acometimento principalmente das 
vias aéreas superiores, o que é confirmado por achados no hemograma, no LBA e na hemogasometria, descritos a seguir.

A temperatura ambiente apresentou queda progressiva do início das avaliações até o D45, apesar de não haver diferença estatística. Os valores mínimos durante os dias permaneceram entre 15 e $20^{\circ} \mathrm{C}$, e os máximos entre 25 e $30^{\circ} \mathrm{C}$. Entre o D15 e o D30, foram observadas as menores médias de temperaturas mínima $\left(15,68 \pm 3^{\circ} \mathrm{C}\right)$ e média $\left(20,69 \pm 3^{\circ} \mathrm{C}\right)$, relacionadas à segunda menor média de umidade relativa mínima do ar $(49,1 \%)$. Em $20 \%$ do grupo PASTO, observou-se a presença de tosse após o D15, podendo esse sintoma estar relacionado, segundo Almeida et al. (2015) a temperaturas amenas e/ou à umidade relativa do ar diminuída.

No leucograma, foi observado que a contagem de eosinófilos do grupo SE apresentou valores maiores e diferentes no basal (Tab. 1). As demais variáveis mensuradas no leucograma não apresentaram diferença significativa. Em concordância com Costa (2012), que relata que afecções de caráter alérgico do sistema respiratório normalmente apresentam exames hematológicos inalterados, neste trabalho foram observados os valores hematológicos dentro da normalidade. Apesar de somente o grupo SE apresentar variações significativas para contagem eosinofílica (decréscimo no decorrer dos momentos), ambos os grupos embaiados (SE e MA) demonstraram queda numérica desse tipo celular. Esse achado pode ser decorrente das condições experimentais (galpão, condições climáticas internas deste e manejo) favoráveis à sanidade das vias aéreas em comparação ao tratamento anterior às avaliações, no qual todos os animais estavam a pasto.

A concentração de fibrinogênio sérico demonstrou diferença numérica $(\mathrm{P}>0,5)$ das médias avaliadas, chegando a triplicar do basal para o D45 em todos os grupos (Tab. 2). Essa observação condiz com o que Costa (2012) relata, sendo associada à reação inflamatória moderada em resposta ao processo alérgico que se instalou nas vias aéreas superiores.

Tabela 1. Médias \pm desvio-padrão da média dos eosinófilos (x $10^{3} / \mu \mathrm{L}$ ) mensurados no sangue venoso de equinos divididos em três grupos: cama de maravalha autoclavada (MA), serragem comum (SE) e piquete (PASTO), nos momentos basal (D0) e quinzenais (D15, D30, D45), realizados após início das avaliações

\begin{tabular}{|c|c|c|c|c|c|c|c|c|}
\hline \multirow{2}{*}{ Grupos } & \multicolumn{8}{|c|}{ Momentos } \\
\hline & D0 & & D15 & & D30 & & D45 & \\
\hline MA & 0,500 & $\pm 0,24$ & 0,350 & $\pm 0,71$ & 0,200 & $\pm 0,03$ & 0,330 & $\pm 0,07$ \\
\hline SE & 0,470 & $\pm 0,11^{\mathrm{a}}$ & 0,340 & $\pm 0,12^{\mathrm{ab}}$ & 0,210 & $\pm 0,06^{\mathrm{b}}$ & 0,204 & $\pm 0,04^{\mathrm{b}}$ \\
\hline PASTO & 0,456 & $\pm 0,24$ & 0,366 & $\pm 0,11$ & 0,282 & $\pm 0,70$ & 0,426 & $\pm 0,18$ \\
\hline
\end{tabular}

Médias seguidas de letras distintas nas linhas diferem entre si $(\mathrm{P}<0,05)$.

Tabela 2. Médias \pm desvio-padrão da média do fibrinogênio ( $\mathrm{g} / \mathrm{dL}$ ) mensurado no sangue venoso de equinos divididos em três grupos: cama de maravalha autoclavada (MA), serragem comum (SE) e piquete (PASTO), nos momentos basal (D0) e quinzenais (D15, D30, D45), realizados após início das avaliações

\begin{tabular}{llllllllllll}
\hline Grupos & D0 & & \multicolumn{3}{c}{ D15 } & \multicolumn{3}{c}{ D30 } & \multicolumn{3}{c}{ D45 } \\
\hline MA & 0,4 & $\pm 0,24$ & a & 0,42 & $\pm 0,23$ & a & 0,4 & $\pm 0,14$ & a & 0,76 & $\pm 0,30$ \\
SE & 0,46 & $\pm 0,37$ & a & 0,22 & $\pm 0,04$ & a & 0,42 & $\pm 0,28$ & a & 1,26 & $\pm 0,88$ \\
Pasto & 0,66 & $\pm 0,75$ & a & 0,32 & $\pm 0,16$ & a & 0,6 & $\pm 0,56$ & a & 1,46 & $\pm 1,27$ \\
\hline
\end{tabular}

A concentração arterial de bicarbonato $\left(\mathrm{HCO}_{3}\right)$ do grupo PASTO (verde, na Fig. 3) apresentou maiores médias em todos os momentos dos demais grupos (MA e SE), porém só havendo diferença estatística no D15 (no qual apresentou maior média) e no D45 (primeiro gráfico da Fig. 3) $(\mathrm{P}<0,05)$. O grupo MA (azul, na Fig. 3) apresentou menores médias de pressão parcial de dióxido de carbono $\left(\mathrm{PCO}_{2}\right)$ significativamente diferentes que o grupo PASTO no D45 (segundo gráfico da Fig. 3). As médias da pressão parcial de oxigênio $\left(\mathrm{PO}^{2}\right)$ apresentaram resultados inversamente proporcionais aos descritos para $\mathrm{PCO}_{2}$, tendo o grupo MA obtido maiores valores do que o grupo PASTO no D45 $(\mathrm{P}<0,05)$ (terceiro gráfico da Fig. 3). 

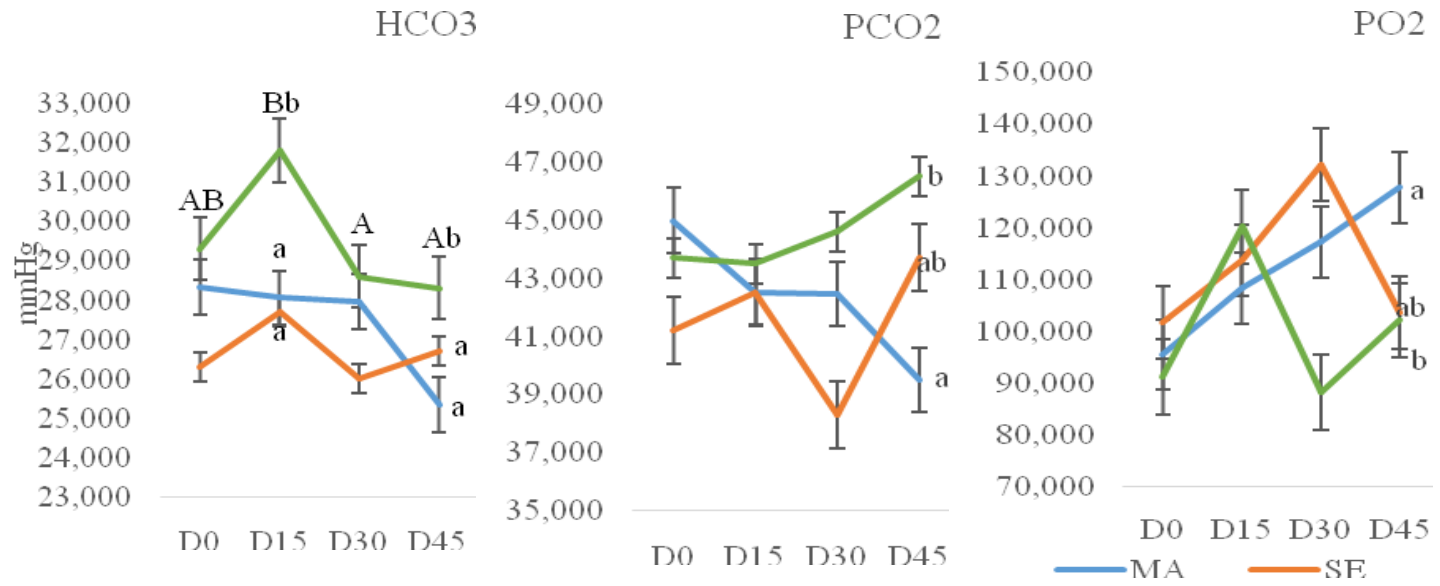

Figura 3. Médias \pm erro-padrão da média de dióxido de carbono $\left(\mathrm{PCO}_{2}\right)$, pressão parcial de oxigênio $\left(\mathrm{PO}_{2}\right)$ e bicarbonato $\left(\mathrm{HCO}_{3}\right)$, mensurados em sangue arterial de equinos divididos em três grupos (MA: cama de maravalha autoclavada - azul, SE: cama de serragem comum - laranja e PASTO: animais em piquete - verde), no momento basal (D0), e posteriores avaliações quinzenais (D15, D30 e D45). Médias seguidas por letras maiúsculas distintas diferem entre os momentos $(\mathrm{P} \leq 0,05)$. Médias seguidas por letras

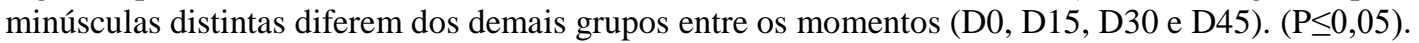

$\mathrm{Na}$ espécie equina, são considerados hipoxemia valores de $\mathrm{PO}_{2}$ inferiores a $80 \mathrm{mmHg}$ e hipercapnia valores de $\mathrm{PCO}_{2}$ superiores a $45 \mathrm{mmHg}$ (Taylor et al., 2010), valores esses não encontrados nesses animais, demonstrando que não houve comprometimento da função pulmonar. O grupo MA apresentou valores de $\mathrm{PCO}_{2}$ menores no D45 (Fig. 3) em relação aos demais grupos, além de diminuição numérica $(\mathrm{P}>0,05)$ dos valores no decorrer dos momentos. Esse achado sugere que o grupo MA teve menor processo irritativo das vias aéreas e consequentemente melhor aproveitamento de oxigênio e excreção de dióxido de carbono com o passar dos momentos. Especula-se, portanto, que cama de maravalha influenciou positivamente nas trocas gasosas (oxigênio e dióxido de carbono), propiciando um ambiente menos alergênico que a SE e o PASTO, além de favorecer a higienização diária sendo mais rápida e efetiva. Na análise citológica do LBA (Fig. 4), observa-se infiltrado de células nucleadas (linfócitos, macrófagos, neutrófilos segmentados e eosinófilos).

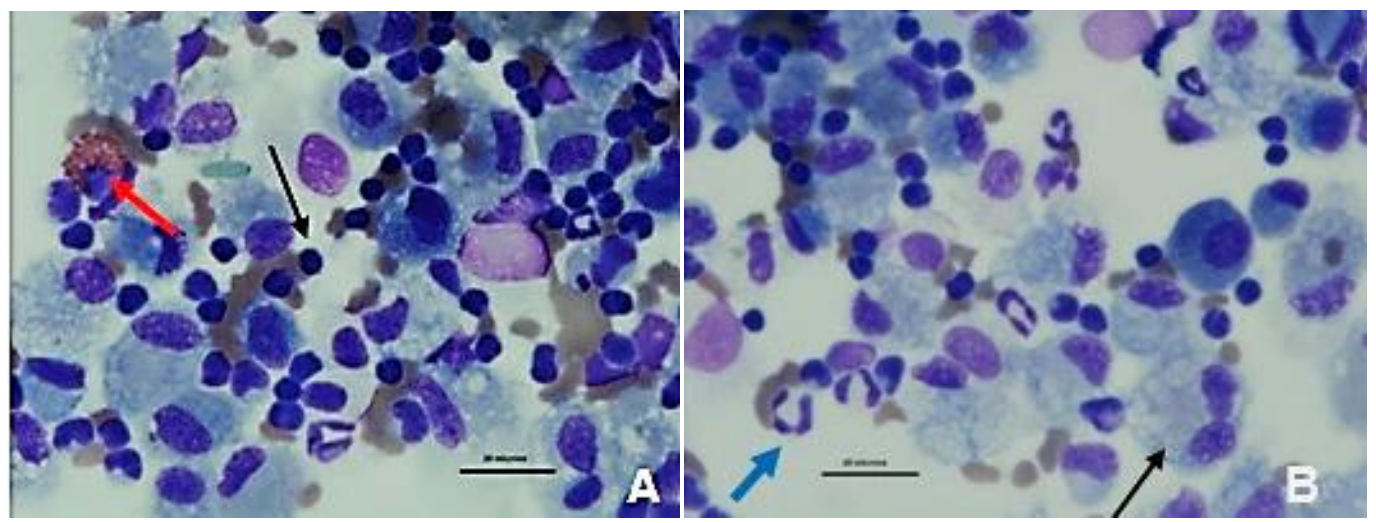

Figura 4. Fotomicrografias de análise citológica de LBA de equino. A) Eosinófilo (seta vermelha), linfócito (seta preta). B) Macrófago (seta preta), neutrófilo (seta azul), panótico, 100x. 
A contagem de células nucleadas totais (CNT) do LBA é descrita na Fig. 5, na qual os três grupos saem de valores basais próximos, porém o grupo PASTO seguiu um padrão crescente e com as maiores médias entre os grupos. Já o MA diminuiu entre o D0 e o momento D15 (P>0,05). Segundo os autores Holcombe et al. (2001), Hodgson e Hodgson (2007), Clements e Pirie (2007) e Bernedt et al. (2008), os equinos estabulados apresentam proporção maior de células inflamatórias no LBA quando comparados a animais mantidos a pasto, devido à maior porcentagem de partículas inaladas nas baias. Ao contrário dessa afirmação, a contagem de CNT do grupo PASTO foi maior, mas não significativa $(\mathrm{P}>0,05)$, que a dos grupos estabulados, independentemente do momento. Quando se comparam apenas os grupos estabulados MA e SE, o segundo grupo, com exceção do momento D45, apresentou CNT maior que o MA, sugerindo que a serragem comum apresenta maior capacidade irritativa das vias aéreas que a maravalha autoclavada, o que condiz com os achados hemosométricos descritos anteriormente.

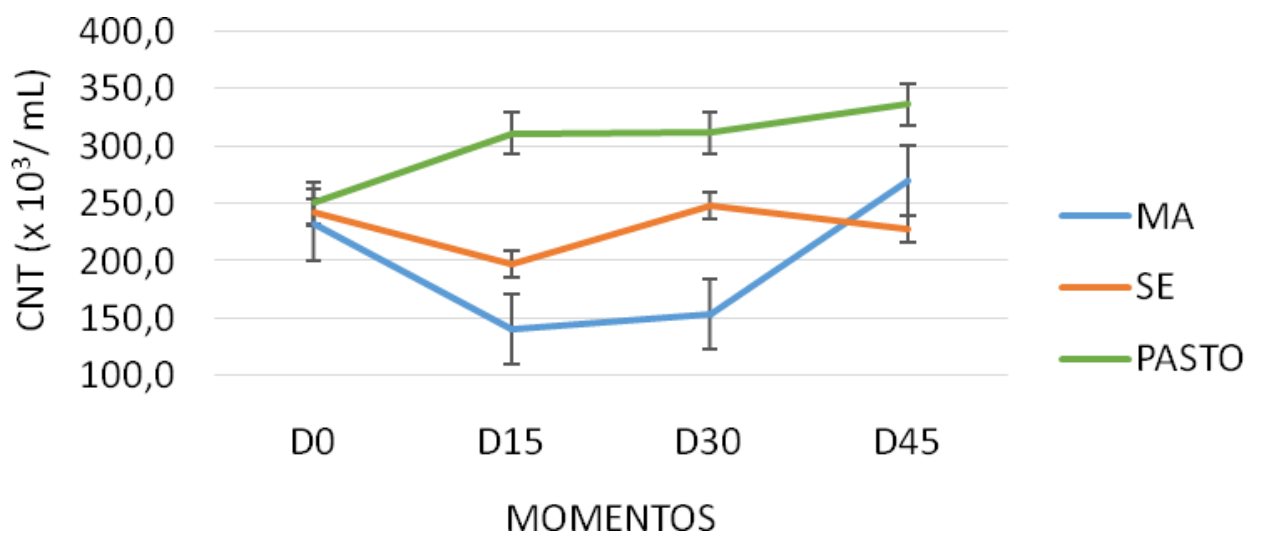

Figura 5. Médias \pm erro-padrão da média das células nucleadas totais (CNT) mensuradas no lavado broncoalveolar de equinos divididos em três grupos (MA: cama de maravalha autoclavada, SE: cama de serragem comum e PASTO: animais em piquete), no momento basal (D0), e posteriores avaliações quinzenais (D15, D30 e D45).

Os valores obtidos na avaliação citológica diferencial do LBA são descritos na Tab. 3. Observou-se diferença no percentual de neutrófilos entre os grupos no momento D30, quando 0 MA apresentou média significativamente maior $(\mathrm{P}<0,05)$. Os neutrófilos são um tipo celular altamente responsivo à estimulação por partículas irritantes no trato respiratório, tendo a capacidade de migrar para o foco de irritação em cinco horas após o estímulo (Léguillette, 2003; Couëtil et al., 2007). Michelotto (2010) associa o aumento de neutrófilos no LBA em estudos com curto período de exposição (período embaiado) à cama utilizada, uma vez que nestes foi utilizada palha, a qual possui caráter alergênico maior que a serragem. Debrue et al. (2005) observaram cavalos com idades entre 8 e 16 anos, de diferentes raças, após 35 dias de estabulação em baias com cama de palha, e obtiveram aumento significativo de neutrófilos no LBA tanto no grupo controle (saudáveis) como no doente (animais com histórico clínico de ORVA). Tendo em vista os períodos de estabulação avaliados pelos autores, o período de 45 dias avaliado neste trabalho apresenta-se suficiente e adequado para desencadear sinais inflamatórios clínicos, como foi observado em alguns animais, além de alterações no LBA, como aumento de neutrófilos. A diferença de intensidade dos sinais e achados laboratoriais entre os animais pode estar relacionada à predisposição individual, assim como descrito por Tremblay et al. (1993) e Leclere (2011). Neste trabalho, não foi observada diferença na contagem de neutrófilos entre os equinos estabulados e a pasto, diferentemente do relatado por Debrue et al. (2005) e Michelotto (2010). Considera-se, portanto, que o ambiente das baias e das camas utilizadas não foi suficientemente irritante às vias aéreas inferiores. 
Tabela 3. Médias \pm desvio-padrão da média do percentual de neutrófilos (NS) e linfócitos (LF) mensurados no LBA de equinos divididos em três grupos: cama de maravalha autoclavada (MA), serragem comum (SE) e piquete (PASTO), nos momentos basal (D0) e quinzenais (D15, D30, D45), realizados após início das avaliações

\begin{tabular}{llllllllllllll}
\hline Grupo & D0 & \multicolumn{3}{c}{ D15 } & \multicolumn{1}{c}{ D30 } & & D45 & \\
\hline MA & 12,80 & $\pm 5,79$ & a & 8,20 & $\pm 5,54$ & ac & 35,00 & $\pm 18,87$ & Ab & 4,80 & $\pm 2,80$ & c \\
SE & NS & 21,00 & $\pm 14,44$ & a & 10,40 & $\pm 2,79$ & a & 16,40 & $\pm 2,88$ & Ba & 4,40 & $\pm 2,97$ & a \\
PASTO & 18,00 & $\pm 12,14$ & & 15,60 & $\pm 3,36$ & & 9,40 & $\pm 4,80$ & B & 7,80 & $\pm 3,35$ & \\
MA & 71,80 & $\pm 14,44$ & a & 66,60 & $\pm 15,53$ & a & 41,60 & $\pm 6,70$ & b & 78,40 & $\pm 5,50$ & ac \\
SE & LF & 71,80 & $\pm 13,81$ & ab & 66,60 & $\pm 6,99$ & ab & 58,20 & $\pm 7,05$ & b & 80,80 & $\pm 4,87$ & a \\
PASTO & & 72,40 & $\pm 9,86$ & a & 51,20 & $\pm 13,57$ & b & 56,50 & $\pm 4,98$ & b & 80,20 & $\pm 1,92$ & a \\
\hline
\end{tabular}

Médias seguidas de letras maiúsculas distintas nas colunas (parâmetro NS) e minúsculas nas linhas diferem entre si $(\mathrm{P}<0,05)$.

Utilizou-se o volume de $180 \mathrm{~mL}$ tendo os valores médios de NS obtidos da análise citológica em D0 variado de 12,8 a $21 \%$, sendo maior que o obtido pelos autores, que utilizaram $250 \mathrm{~mL}$ (Robinson, 2001; Hewson, Viel, 2002; Hodgson, Hodgson, 2007). Este achado condiz com a afirmação de Lessa et al. (2011), não sendo adequado utilizar como referência os valores de LBA adquiridos com volumes infundidos diferentes. Hoffman et al. (2003), Viel e Hewson (2001) consideram, para equinos sadios, contagens percentuais inferiores a $5 \%$, o que não foi observado no D0 deste trabalho. Tais diferenças podem corroborar as afirmações quanto aos volumes diferentes de infusão entre os trabalhos comparados, sendo que o valor de neutrófilos pode estar superestimado quando se compara a trabalhos que usaram volumes maiores. Entretanto, os valores entre os grupos foram uniformes, sendo passíveis de comparação e de conclusões quanto ao fator alergênico das camas comparadas ao pasto.

As características descritas do pavilhão de cocheiras utilizado, com ventilação, higienização e manejo correto dos animais, favoreceu a sanidade do sistema respiratório dos equinos, corroborando as afirmações de Derksen e Woods (1994). Assim, poucos animais apresentaram sinais sutis de irritação das vias aéreas, o que trouxe informações de manejo ideais ao setor equestre para a região na qual foi realizado o estudo.

\section{CONCLUSÃO}

Os tipos de cama testados no presente estudo não apresentam diferença na capacidade de desencadear resposta inflamatória alérgica das vias aéreas dos equinos no período analisado.

\section{REFERÊNCIAS}

AINSWORTH, D.M.; CHEETHAM, J. Disorders of the respiratory system: diagnostic approach to respiratory disorders. In: REED, S.M.; BAYLY, W.M.; SELLON, D.C. Equine internal medicine. 2.ed. St. Louis, Missouri: Elsevier Saunders, 2010. p.289-341.

ALMEIDA, S.R.P.; ROCHA, D.C.C.; LOPES, A.C.A.M.; et al. The use of tracheal wash and bronchoalveolar lavage in the clinical examination of coughing horses. Rev. Acad. Ciênc. Anim., v.13, p.81-89, 2015.

BERNDT, A.; DERKSEN, F.J.; ROBINSON, N.E. Endotoxin concentrations within the breathing zone of horses are higher in stables than on pasture. Vet J., v.183, p.54-57, 2008.

CLEMENTS, J.M.; PIRIE, R.S. Respirable dust concentrations in equine stables. Part2: the benefits of soaking hay and optimizing the environment in a neighbouring stable. Res. Vet. Sci., v.83, p.263-268, 2007.

CLUTTON, R.E. Blood gas analysis. In B.C. MCGORUM, P.M.; DIXON, N.E. ROBINSON; SCHUMACHER, J. (Eds.). Equine respiratory medicine and surgery. Philadelphia: Elsevier Saunders, 2007. p.201-209.

COSTA, L.R.R. Summer Pasture-associated recurrent airway obstruction. In WILSON D.A. Clinical veterinary advisor: the horse. St. Louis, Missouri: Elsevier Saunders, 2012, p.591-593.

COUËTIL, L.L.; HOFFMAN, A.M.; HODGSON, J. et al. Inflammatory airway disease of horses. J. Vet. Int. Med., v.21, p.356361, 2007. 
DEBRUE, M.; HAMILTON, E.; JOUBERT, P.; et al. Chronic exacerbation of equine heavesis associated with an increased expression of interleukin-17 mRNA in bronchoalveolar lavage cells. Veterinary Immunology and Immunopathology. v.105, p. 25-31. 2005.

DERKSEN, F.J.; WOODS, P.S.A. Chronic lung disease in the horse: role of aeroallergens and irritants and methods of evaluation. Vet. Clin. N. Am. Equine Pract., v.16, p.11-13, 1994.

GUTH, A.M.; JANSSEN, W.J.; BOSIO, C.M. et al. Lung environment determines unique phenotype of alveolar macrophages. Am. J. Physio-Lung Cel. Mol. Physiol., v.296, p.936946, 2009.

HEWSON, J.; VIEL, L. Sampling, microbiology and cytology of the respiratory tract. In: LEKEUX, P. Equine respiratory diseases. Ithaca: International Veterinary Information Service, 2002. Available in <http://www.ivis.org/special_

books/Lekeux/viel/chapter_FRm.asp?LA=1>. Accessed in: 5 Jan. 2016

HODGSON, J.L.; HODGSON, D.R. Tracheal aspirates: indications, technique, and interpretation. In: ROBINSON, N.E. Current therapy in equine medicine. 5.ed. St.Louis: Saunders, 2007. p.401-407.

HOFFMAN, A.; ROBINSON, N.E.; WADE, J.F. Workshop summary. In.: WORKSHOP ON INFLAMMATORY AIRWAY DISEASE: DEFINING THE SYNDROME, 2003, Boston. Proceedings... Boston: R \& W Publications, 2003. p.89-91, 2003.

HOLCOMBE, S.J.; JACKSON, C.; GERBER, V. et al. Stabling is associated with airway inflammation in young Arabian horses. Equine Vet. J., v.33, p.244-249, 2001.

HOROHOV, D.W., Immunology of the equine lung. In: LEKEUX, P. (Ed.). Equine respiratory diseases. Ithaca, NY: International Veterinary Information Service. 2004. Available in: <http://www.medivetequine.com/wpcontent/ uploads/2014/12/ACS-Immunology-of-theEquine-Lung.pdf >. Accessed in: 5 Jan. 2016.

HUME, D.A. Macrophages as APC and the dendritic cell myth. J. Immunol., v.181, p.58295835, 2008. Available in: <http://www.jimunol.org>. Accessed in: 5 Jan. 2016.
ITO, S.; HOBO, S.; KASASHIMA,Y. I. Bronchoalveolar lavage fluids findings in the atelectatic regions of anesthetized horses. J. Vet. Med. Sci., v.65, p.1011-1013, 2003.

LECLERE, M.; LAVOIE-LAMOUREUX, A.; GELINAS-LYMBURNER, E. et al. Effect of antigen exposure on airway smooth muscle remodeling in an equine model of chronic asthma. Am. J. Resp. Cel. Mol. Bio., v.45, p.181187, 2011.

LÉGUILLETTE, R. Recurrent airway obstruction - heaves. Vet. Clin. N. Am. Equine Pract., v.19, p.63-86, 2003.

LESSA, D.A.B.; JORGE M.L.L.A.; VIANA, E.B.; FERNANDES, W.R. Análise do líquido broncoalveolar de equinos portadores de doença inflamatória das vias aéreas. Braz. J. Vet. Res. Anim. Sci., v.48. p.123-130, 2011.

LUNN, D.P.; BREATHNACH, C.; SOBOLL, G. Immunology and Immunopathology. In: McGORUM, B.C.; DIXON, P.M.; ROBINSON, N.E.; SCHUMACHER, J. Equine respiratory medical surgery. Philadelphia: Elsevier, 2007. p.71-81.

McGORUM, B.C.; DIXON, P.M. Clinical examination of the respiratory tract. In: MCGORUM, B.C.; DIXON, P.M.; ROBINSON, N.E.; SCHUMACHER, J. (Eds.). Equine respiratory medicine and surgery. Philadelphia: Elsevier Saunders, 2007. p.103-117.

MICHELOTTO JR, P.V. Efeitos do desafio ambiental e do exercício na funcionalidadedos macrófagos do Lavado Broncoalveolar de cavalos puro sangue Inglês de corrida. 2010, 113f. Tese (Doutorado em Medicina Veterinária) - Faculdade de Veterinária - Universidade Federal do Paraná, Curitiba, PR.

PILETTE, C.; OUADRHIRI Y.; GODDING, V.; et al. Lung mucosal immunity: immunoglobulin - A revisited. Eur. Resp. J., v.18, p.571-588, 2001.

ROBINSON, N.E. International workshop on equine chronic airway disease. Equine Vet. J., v.33, p.5-19, 2001. 
ROBINSON, N.E.; FURLOW, P.W. Anatomy of the respiratory system. In MCGORUM, B.C.; DIXON, P.M.; ROBINSON, N.E. et al. (Eds.). Equine respiratory medicine and surgery.Philadelphia: Elsevier Saunders, 2007. p.3-18.

TAYLOR, I.G.R.; BRAZIL, T.J.; HILLYER, M.H. Respiratory diseases. In: Diagnostic techniques in equine medicine. 2.ed. London: Saunders Elsevier. 2010. p.217-248.

THACKER, E.L. Lung inflammatory responses. Vet Res., v.37, p.469-486, 2006.

THOMASSIAN, A. Principais afecções das vias aéreas anteriores do equinos. In: SIMPÓSIO ALAGOANO DE MEDICINA EQUINA, 2., 2012, Maceió. Anais... Brasilian Journal of Equine Medicine - Suplemento I (40). Maceió: UFAL, 2012. p.106-114.

TREMBLAY, G.M.; FERLAND, C.; LAPOINTE, J.M. et al. Effect of stabling bonbronchoalveolar cells obtained from normal and COPD horses. Equine Vet. J., v.25, p.194$197,1993$.
VIEL, L. Diagnostic methodologies: RAO and IAD. In: PROCEEDINGS OF THE AIRWAY SYMPOSIUM, 4., 2009, Berne. Proceedings... Berne: International Veterinary Information Service, 2009.

VIEL, L.; HEWSON, J. Bal cytology in horses with exercise intolerance: what does it tell us? In: WORLD EQUINE AIRWAYS SYMPOSIUM, 2001, Edinburgh. Proceedings... Edinburgh, 2001. Available in: <http://www.ivis.org/ proceedings/weas/2001/Viel.pdf > Accessed in: 17 Jan. 2016.

WIEDMEYER, C. Blood gas analysis. In WILSON, D.A. Clinical veterinary advisor: the horse. St. Louis, Missouri: Elsevier Saunders, 2012. p.913.

WILKINS, P.A. Diseases of the respiratory system. diagnostic procedures for the respiratory system. In: SMITH, B.P. Large animal internal medicine. 4.ed. St. Louis, Missouri: Mosby, 2009. p.490-551. 